\title{
Teacher Empowerment in Education Practice: Strategies, Constraints and Suggestions
}

\author{
Kimwarey M. C*; Chirure H.N ${ }^{1}$; Omondi $\mathrm{M}^{1}$. \\ Moi University-School of Education P.O Box 3900-30100 Eldoret-KENYA
}

\begin{abstract}
Education is a gradual process through which individuals acquire general to specific knowledge, skills, information and attitude from educators that would enable them develop powers of reasoning and judgment in their everyday experiences. This makes it an empowerment process as individual over time attain rightful status in the society. It is in this that the role of the teacher may not be overlooked but rather be emphasized as they remain to be the main contributors towards student learning. But for educators to be able to accomplish this noble task they need to constantly learn, unlearn and relearn in order to gain more knowledge, skills and right attitude towards their role. This entails empowering themselves with the right knowledge, skills, attitudes and development of competence that would enable them respond adequately to challenging and demanding needs of the modern society. This demands that empowerment be a continuous process where individuals are developed, a journey where people gain lifelong experiences which would enable them exercise power over their own practices and circumstances. As a result of this, educators are therefore expected to respond adequately to the pressing and dynamic demands of the modern world, those of the educational community, to act professionally and be able to use their expertise to guarantee successful education process for our youth. It is for this reasons that the writers of the paper looks into why we need to empower teachers amidst their busy and demanding task, strategies the school management as well as individuals may use to empower themselves and possible constraints that may hamper the empowering process. It is our hope that this will shade light on the importance of empowerment and strategies to be utilized in the $21^{\text {st }}$ century where there is a paradigm shift on the role of the teacher.
\end{abstract}

Key words: Education, teacher empowerment and response, challenges and prospects.

Education is a gradual process through which individuals acquire general knowledge; skills and information from the teachers that would enable them develop powers of reasoning and judgment in their everyday experiences. It is integral to preparation for and legitimization of particular forms of social life that is closely linked to individual responsibility and economic wellbeing. It contributes to realization of a variety of different human capacities, encourages development of competencies, capabilities and expands meaning of what is to be human. In this case education should be an empowering process that will enable one to attain a rightful status to claim economic, social and political and cultural spheres as well as being able to fully participate in the community. However, for this to be realized the role of the teacher cannot be overlooked as she/he is the main contributor to student learning making their outcome to be widely recognized. The teacher effectiveness has a lot of impact on the student learning. For one to be able to meaningfully transmit knowledge, skills and right attitude continuous learning, relearning and unlearning is necessary. In the present time, myriad changes calls for any individual to adapt and adopt to changing needs and circumstances in the society making an education process an important cycle where knowledge and skills and right attitudes are transmitted especially in this $21^{\text {st }}$ century. Among many other issues globalization has attracted and brought about ever changing dynamics in the modern world which have posed challenges in all fields including the emergence of technological innovations such as information technology that has made our world economy to be interconnected in a small global village. The experience has either opened up the world to favorable international relations or posed a challenge that has called for the need for constant continued updates of knowledge. Notwithstanding the demands of the present employers either in business world, government institutions, community or non-governmental organizations who demand the formation of a new type of professionals, ones who are capable of dealing with the unexpected and the complex situations. Not ignoring is the changing demographic fabric of our communities which has brought us into daily contact with people from around the globe via IT systems such as e-mails, fax, social media among others either in business connections and academia among others. The questions that are likely to be posed are: Are our educators empowered with the right knowledge, skills and attitudes to either facilitate or contribute to this reality? Are our administrators and teachers adequately prepared with updated knowledge, skills and positive attitude? Do schools have adequate instructional resources to making learning manageable? Are there organized frequent professional development courses that empower the teachers with new knowledge and skills to face these tasks? The answers of the above depend on whether educators are constantly empowered with the knowledge and skills. 


\section{Empowerment}

According to Rappoport (1988) the word empowerment has attracted a number of definitions based on context used and this is in agreement Page and Czuba (1999) who see empowerment having no clear definition as it is used across disciplines. However they report it as a multi-dimensional social process which helps people gain control over their own lives and society. It is social since it occurs in relation to others and it is a process since it is similar to a journey where people develop through it and where individuals gain and exercise power over their own practices and circumstances. When accomplished in the course of time, individuals gain the authority over something and are able to utilize the knowledge gained. Similarly it a transformative process which when well accomplished socio-cultural interactions are enhanced enabling individuals to attain personal and professional objectives. Lastly it can be equated to a vehicle where individuals increase power for and expand their capacity to criticize issues they find that may be subjective to them or agree with. From the above empowerment can be said to be a process where an individual self-discovers his/her potential and limitations in an effort to search for better future.

In the education sector educational empowerment can be said to be a process where school participants develop the competence to take charge of their own growth and from it are able to address or resolve their own problems by developing mechanism to do so. An empowered individual is said to have the skills and knowledge to act on a situation or even improve it in a positive way. However, for this to be realized school setting should provide opportunities for development and a display of competence in handling diverse situations making teachers to be central in this process (Frymier, 1987). In the recent past the culture of schools have changes significantly forcing experienced teachers stop functioning in isolation and start solving problems related to students' learning collectively (Rosenholtz, 1991). This means that any attempt made to improve schools must pay attention to individual role in decision making, increased opportunities for meaningful and collective participation in the critical areas of activity of the schools while focusing on organizational goals. Therefore the effort to restructure schools towards improvement is critical and an important component where all stakeholders teachers, administrators and students empowerment cannot be overlooked (Murphy \& Evertson, 1990; Short et al, 1991). For it is through the actions of an empowered teacher and administrators that students are made to benefit. Irwin (1991) sees an empowered educator as one who believes in himself/herself and his/her ability of action, understands the system of domination and dedicates time and energy towards the improvement of oppressive practices in the society, respects others and uses his/her power to protect the uniqueness of individuals. Whether working alone or with each other people, they are firm, practical, and passionate dedicated to the self-realization of students in the classroom, at school, and in the community.

Therefore, for education systems to be improved the teacher is one of the variables that must be changed (Eleonora, 2003). Teachers are expected to respond adequately to the pressing demands of the modern world and to the growing concerns of the educational community, expected to be highly professional and to have considerable expertise so as to guarantee qualified and successful educational processes and practices.

Harpell \& Andrews, (2010) sees teacher empowerment as the confidence to make and the power to enact situational appropriate instructional decisions that improve the quality of education for students. That they need to have a broader voice in educational affairs of the learners which can only be attained where teacher preparation as well continued updates of teacher's competence is done. Mores so the everyday experiences faced as well as the numerous challenges demand an understanding and development of mechanisms to be used to overcome them through effective practices. This may be made possible either by participating in decision making in their area of operation or ensure the existence of harmony and collaboration among all stakeholders as they are central shapers of education. In the process teacher empowerment becomes a crucial process as it enable one develop personal competence, ability to act and even provide an opportunity to demonstrate and display their competence where opportunity is provided.

Thomas and Velthouse (1990) argue that for this to be possible an empowering environment should be provided because it fosters the development of intrinsic motivations which in turn promote and facilitate a change in teacher practice. The intrinsic change will affect the behavior of the teacher in terms of approach to work, in one's instructional approach, materials utilized; teaching procedures which eventually leads to a change in student learning outcomes. The teachers' perceptions of the improvement in their students' learning then translate into a change in teachers' attitudes and beliefs. Harpell \& Andrews (2010) sees this as an attitudinal shift which leads to increased intrinsic motivation that is necessary for the creation of an empowering environment.

Maeroff (1988) suggests that empowerment begins with the boosting of teacher status where they are treated like the professionals and by this they retain control over their own practice and over the decisions that affect their own classrooms. It is strongly correlated to task motivation. He further provides two additional elements that are essential for teacher empowerment: an increase in knowledge and the opportunity to collaborate with colleagues where their roles are distributed increasing opportunities for meaningful collective participation. It is for this reason that continued professional development and updating of knowledge needs to be emphasized for 
without this educators will lack the power to enact instructional decisions in a manner that is appropriate to their educational situation. Velthouse et, al.,(1990) provides four components of empowerment process: choice for enrichment, opportunity to have their voice heard, provided with the power for control and influence over instructional process, development and display of competence in decision making, meaningfulness as concerns valuing the work done by the empowered teacher and teachers actual influence over what is going on in school while ensuring their decisions make a difference.

Short(1994) outlines six dimensions of empowerment which include: professional development where teachers are provided with opportunities to grow, develop, learn continuously so as to expand one's own skills and be able to utilize the knowledge gained to improve their work; teachers' autonomy in decision making and to be able to control aspects of their work life which is likely to makes them confident in whatever they do and in areas that affect directly their work; staff workload, teaching methods among others; their impact and influence in daily contact has a direct impact on their perception of how the school treats them and which either positively or negatively affect their daily activities. At a personal level, how the school treats an individual teacher either with respect on their professional knowledge and the genuine support from colleagues. Lastly, is the teacher's self-efficacy which is their perception that one has skills to help students learn and even are competent in building effective support programs that will in the end produce positive changes in student learning.

Therefore, owing to dynamic nature of our society especially in the $21^{\text {st }}$ century, teacher empowerment cannot be wished away as education reforms and restructuring of schools is inevitable. It is for this reason that questions such as; why is teacher empowerment important in schools? What strategies should governments, schools and individuals do to enhance teacher/individual empowerment? How can schools, students and community benefit from the idea of teacher empowerment?

\section{Why should we empower teachers in schools?}

Teachers need to be empowered so that they can develop the competence to take charge of their own growth and be able to resolve their own problems in their everyday practice. To develop skills and competence needed in making important collaborative decisions and a display of commitment that in turn will create room for significant collaborative participation and democratic understanding. It enables teachers exercise power over their educational lives and even resists controls that are detrimental to their own work. It enables them generate and amplify their voice in educational affairs, develop and improve their pedagogical know-how, enable them to understand how, why, what they do which increases their competence in their areas of specialization. Through it teachers are transformed personally and in collaboration with others in an effort to achieve the objectives of the school. It creates a situation where teachers are able to work closely with the school administration especially on matters that affect them collectively and individually and develop a sense of appreciation which eventually trickles down to personal activities at classroom level. It helps a teacher discover him/herself, be updated on new knowledge which when utilized help to transform teachers every day practices in accomplishing of educational objectives. It enables a teacher to undertake critical and transformative actions towards every day issues and in the process take charge of situations hence establish links between theory and actual practice. Teachers will develop the capacity to reflect and evaluate their academic progress in order to keep abreast with the societal needs.

\section{What strategies should school management and individuals do to enhance teacher/individual empowerment?}

As a teacher educators and a teachers the authors of this work feel that if the following recommendations are accepted and implemented, there is fairly good chance for providing empowering opportunities.

To create opportunities that are formal and informal for teachers to influence, design, create and implement the curriculum hence improve academic qualities for the nation; encourage the inclusions of teachers in community, school and national level discussions related to the well-fare and ability of all students to academically achieve at the highest level; provide teachers access to resources (financial, time, opportunities etc.) to identify and solve problem related to their classroom in order to ensure they can help all students learn; the school management to consider teacher effectiveness for high performance by use of value added scores based on learner performance using national examination performance, qualitative and end-of-course work and where this is not used other factors that impede performance should be looked into so as not to demoralize the teacher; teacher evaluation which over time has not been seen to be objective but punitive rather than a tool to help improve. There is need for cultural shift in belief and behavior in the use of teacher evaluation; continued professional development which is tailored towards teachers identified need based on one's strength or weakness and as such courses be provided that are aligned to areas of improvement. For those who have improved themselves academically and to reduce high attrition, adequate support financial and promotion motivations need to be used. More so 
induction programs should be provided and continued support in order to maintain effective teaching and development of a mentoring program aimed at building teacher effectiveness and ongoing support. However the extent of such support may be tricky as some principals may not be trained adequately to effectively and objectively evaluate teachers and ensure customized professional development is provided.

School administration need to build confidence in their teachers, be allowed to freely express their opinions regarding the everyday issues in the school and try out new techniques to address problems they face, provide a listening ear to their views and followed by discussion among all those concern until a consensus is attained. Failure to create such a safe environment teachers may be reluctant to make changes or test new ideas and the inverse may occur where the administration does not offer express approval to teacher's ideas. Although Sprague (1992) thinks such resistances attract opinions from a number of teachers which is better than acting passively. He suggested that institutional resistance could be the starting point which should not be judged negatively but be assessed if it will contribute to educational betterment and teachers' professional development. Through it teacher's voice is heard as they critique each other, learn to listen to each other, express their opinions and in the end make decisions effectively and collaboratively and in the long run invoke significant changes (Romanish, 1991). Teachers to be allowed to pursue shared leadership, to take control over their work and immediate environment, participate in decision-making and share information to all rather than by few administrators. This is an important strategy leading to increased shared leadership in the present corporate world.

Teachers to be allowed to develop collegiality and in collaboration share experiences in an effort to solve educational problems (Sprague, 1992; Reep \& Grier, 1992) such as in curriculum planning, execution and evaluation, allow interaction and linkage which is critical for empowering teachers (Hallinger \& Richardson, 1988; Irwin, 1996). Develop a program where teachers are prepared and upgraded in other areas such as timetabling, examinations, director of studies a process where future leaders are developed and empowered with skills to take up the task whenever called upon. Develop and establish transformative vision that would not only change the face of the school but change the entire organization and restructure teaching profession as concerns preparation and teaching and use of appropriate teaching methods and instructional materials while taking account of student's individual difference and invoking quantitative and qualitative changes among students.

\section{Constraints towards teacher empowerment}

The nature of teachers work today can be challenging. The demands from the development of technology, increased controls in curriculum and instruction, standardization of teachers' work make teachers maintain little control over their work making the professional abilities and resulting in decline in teachers' status.

The ever increasing enrolment and workload of teachers and their isolated working environment make it hard for teachers to engage in professional discussions and develop strong professional communities. But the question is: are teachers empowered or relatively disempowered? Teachers' sense of disempowerment has a negative impact on their profession. Consequently, empowering teachers becomes an important agenda in teachers' professional development as there is need to increase teachers' power and ability in order to improve their status and ability (Zeichner, 1991)

Another challenge is time factor which affects teacher's everyday activity. Decision making process takes a lot time before a consensus is reached making majority of teachers not be willing to take more responsibility owing to great pressure in balancing two demands teaching and taking part in administrative duty (White, 1992; Zeichner, 1991).

Teachers lack of moral support from other teachers as well as the administration especially when they are tied up with other responsibilities. Some teachers devote their personal time and energy to improve the working relations while others may see those who are often involved in decision making as being favored by the administration especially where decision arrived at did not consider their views.

Lack of training in related field such as team and capacity building programs hamper them from participating in decision making process fairy well. Teacher empowerment is more than the expansion of teachers' power as it also emphasizes the growth of teachers' ability and power to handle diverse circumstances.

The legacy of traditional bureaucracy allows few people to be responsible for making decisions on behalf of others. Where teacher empowerment is encouraged changes the power relations at school, between the administrators and teachers may not be easy since both groups might not be ready for that. According to the African culture orders are made from the top or being made by male and less of women. Therefore having either or any one of them to make decisions might become a burden or a challenge for them (Foster, 1990). Some administrators are not used to taking order or even share their power with other/some teachers who might invoke oppositions from administrators. Thus the legacy from traditional bureaucracy will hinder the realization of teacher empowerment. 


\section{Suggestions for Empowering Teachers}

There is need to make teachers aware of the central position as educators in education process and the need to keep improving and updating their knowledge.

Recognize the fact that all persons have different gifts and skills which can be utilized collaboratively in order to accomplish shared goals

There is need to specify the domains for teacher participation in school decision-making. Though others argue that their role and limit fall within the classroom setting and should not try to participate in all aspects of school management and that they have limited time and energy raises doubt about this allegation. Some people raised serious doubt on the linkage between teachers' participation in school decision-making and the improvement in students' performance. Others argue that teachers' participation in school decision making has a negative impact on students learning while others argue that it is better for teachers to participate in the fields that are directly related to their professional practices (such as teaching and curriculum).

Administrators and teachers need to come to a mutual agreement on both sides' that is the jobs and other responsibilities. Using this as the basis, teachers and administrators can develop successful models of teacher participation in school decision-making and increase the legitimacy and authority of teachers' participation in school management (Conway \& Calzi, 1995; Karant, 1989). However, there is need to specify the rules for teacher participation on who to participate. Organization needs to have clear, well-specified rules for participation so that power won't be the privilege of few members in the organization but should all inclusive so as to act as a motivator to the rest of the teachers.

The teachers' goal in enhancing educational betterment and for students benefit is equally important. That accomplishing teacher empowerment without advancing students' benefit and educational betterment is not considered as real (Conway \& Calzi, 1995; Romanish, 1995).

While discussions are taking place there is need to provide enough time and patience for teacher participation as teacher empowerment is a process, rather than an event. It takes time for schoolteachers to gain the power and ability they need for school participation (Conway \& Calzi, 1995). The result of school participation might not be always successful because some experiments or new trials might not work out. The progress of teacher empowerment is affected by the quality of teachers, the background and personality of principles, the number of programs currently implemented at school and educational expectations (Kirby, Wilmperberg, \& Keaster, 1992).

There is need to consider the background and concerns of individual teachers where negotiation and compromise is necessary recipe for the realization of teacher empowerment (Rosen, 1993). Schools need to be prepared for the possible delays or lack of efficiency due to teacher participation in school management (Mentell, 1993).

There is need to work on traditional legacies that may not be of benefit in today's society. To make all those concerned to realize thoughts and wishes of their colleagues matter and are important especially where decisions to be made may affect the entire organization. In such cases the principal and the school management need to build leaders with structures and climate that empowers both teachers and students and desist from holding on to traditional approach that makes them authoritarian. This is because of a paradigm shift where the decisions are made by those working most closely with students rather than those at the top of the pyramid viz a viz authoritarian leadership that is coercive, manipulative, and controlling. These negative tactics have proven counter-productive. From empowerment research done show the conditions under which teachers work are often set up in such a way as to deny teachers a sense of efficacy, success, and self-worth and too much isolation make teachers becomes bored, resentful, and unhappy. On the other hand, many teachers find themselves working "with" principals instead of "for" principal teachers and to reverse where a general trend toward treating them as employees who do specific tasks planned in detail by other people.

Lastly incorporate all stakeholders before making a final decision affecting issues of concern to entire organization so that non is exclude from participating which enhances harmony between and among all members since isolation, or closure will not win any sincere support as inclusion and interaction will.

It is our sincere hope that by introducing these new paradigms in our Kenyan institutions, the teaching profession will become a truly rewarding experience. 


\section{References}

[1]. Conway, J., A. \&Calzi, F. (1995).The dark side of shared decision making.Educational Leadership, $53(4), 45$.

[2]. Foster, K. (1990). Small steps on the way to teacher empowerment.Educational Leadership, 38-40.

[3]. Hallinger, P., \& Richardson, D. (1988). Models of shared leadership: Evolving structures and relationships. Urban Review, 20(4), 229-245

[4]. Harpell, J. V., \& Andrews, J. J. W. (2010). Administrative leadership in the age of inclusion: Promoting best practices and teacher empowerment. Journal of Educational Thought, 44, 189-210

[5]. Irwin, J. W. (1996). Empowering ourselves and transforming schools: Educators making a difference. Albany, N.Y: State University of New York Press

[6]. Karant, V. I. (1989).Supervision in the age of teacher empowerment.Educational Leadership, May, 27-29.

[7]. Kirby, P. C., \&Wimpelberg, R., \&Keaster, R. (1992). Teacher empowerment depends

[8]. Maeroff, G. I. (1988). The empowerment of teachers. New York: Teachers College Press inhttp://www.questia.com/library/1G1$16138677 /$ defining-teacher-empowerment/

[9]. Mentell, E. J. (1993). Implementing sited-based management: Overcoming the obstacles.NASSP Bulletin, 77(555), 97-102

[10]. Page, N. and Czuba, C. (1999). "Empowerment: What Is It?" Journal of extension, 37(5) ISSN 1077-5315. Available at http://www.joe.org/joe/1999october/comm1.php (accessed on 28 April 2012)

[11]. Rapport, J. (1984). Studies in empowerment: Introduction to the issue. Prevention in Human Services (available http://www.joe.org/joe/1999october/comm1.php (accessed 19/11/2012)

[12]. Romanish, B. (1993)."Teacher Empowerment as the Focus of School Reforming."The School Community Journal, 3(1), 47-60. Available at http://educacionyeducadores.unisabana.edu.co/index.php/eye/article/view/1624/ (accessed 19/11/2012)

[13]. Rosen, M. (1993).Sharing power: A blueprint for collaboration.Principal, 72(3), 37-39.

[14]. Sprague, J. (1992). Critical perspectives on teacher empowerment.Communication Education, 41(2), 181-203

[15]. Short, P. M., \& Rinehart, J. S. (1992). School participant empowerment scale:

[16]. Assessment of level of empowerment within the school environment.Educational and Psychological Measurement, 52(4), 951-960.

[17]. Thomas, K. W., \&Velthouse, B. A. (1990). Cognitive elements of empowerment: An "interpretive model"

[18]. of intrinsic task motivation. Academy of Management Review, 15, 666-681.

[19]. Villegas-Reimers, E. (2003). Teacher Professional Development: An International Review of the Literature. Paris: IIEP UNESCO. Available at http://unesdoc.unesco.org/images/0013/001330/133010e.pdf (accessed 19/11/12)

[20]. White, P. A. (1992). Teacher empowerment under "ideal" school-site autonomy. Educational Evaluation and Policy Analysis, 14(1), 69-82

[21]. Zeichner, K. M. (1991). Contradictions and tensions in the professionalization of teaching and the democratization of schools.Teacher College Record, 92(3), 363-379 